\title{
Correction to: Fungal diversity and metabolomic profiles in GM and isogenic non-GM maize cultivars from Brazil
}

\author{
A. M. Gasperini ${ }^{1} \cdot$ E. Garcia-Cela ${ }^{2} \cdot$ M. Sulyok $^{3} \cdot$ A. Medina ${ }^{1} \cdot$ N. Magan ${ }^{1}$
}

Published online: 11 November 2020

(C) Society for Mycotoxin (Research Gesellschaft für Mykotoxinforschung e.V.) and Springer-Verlag GmbH Germany, part of Springer Nature 2020

\section{Correction to: Mycotoxin Research https://doi.org/10.1007/s12550-020-00414-8}

The original version of this paper was published with an error. The Corresponding author noticed that the first authors' initial is missing: this should be "A.M. Gasperini" instead of "M. Gasperini". The original manuscript had the right initials. This is the corrected author name.

The original article has been corrected.

Publisher's note Springer Nature remains neutral with regard to jurisdictional claims in published maps and institutional affiliations.

The online version of the original article can be found at https://doi.org/ 10.1007/s12550-020-00414-8

N. Magan

n.magan@cranfield.ac.uk

1 Applied Mycology Group, Environment and AgriFood Theme, Cranfield University, Cranfield, Bedfordshire MK43 0AL, UK

2 Biological and Environmental Sciences, School of Life and Medical Sciences, University of Hertfordshire, Hatfield AL10 9AB, UK

3 Institute of Bioanalytics and Agro-Metabolomics, Department of Agrobiotechnology (IFA-Tulln), University of Natural Resources and Life Sciences, Konrad Lorenzstr. 20, A-3430 Tulln,

Vienna, Austria 